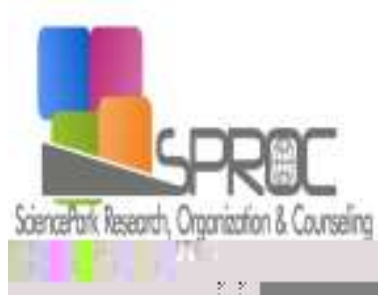

$\mathrm{H}$
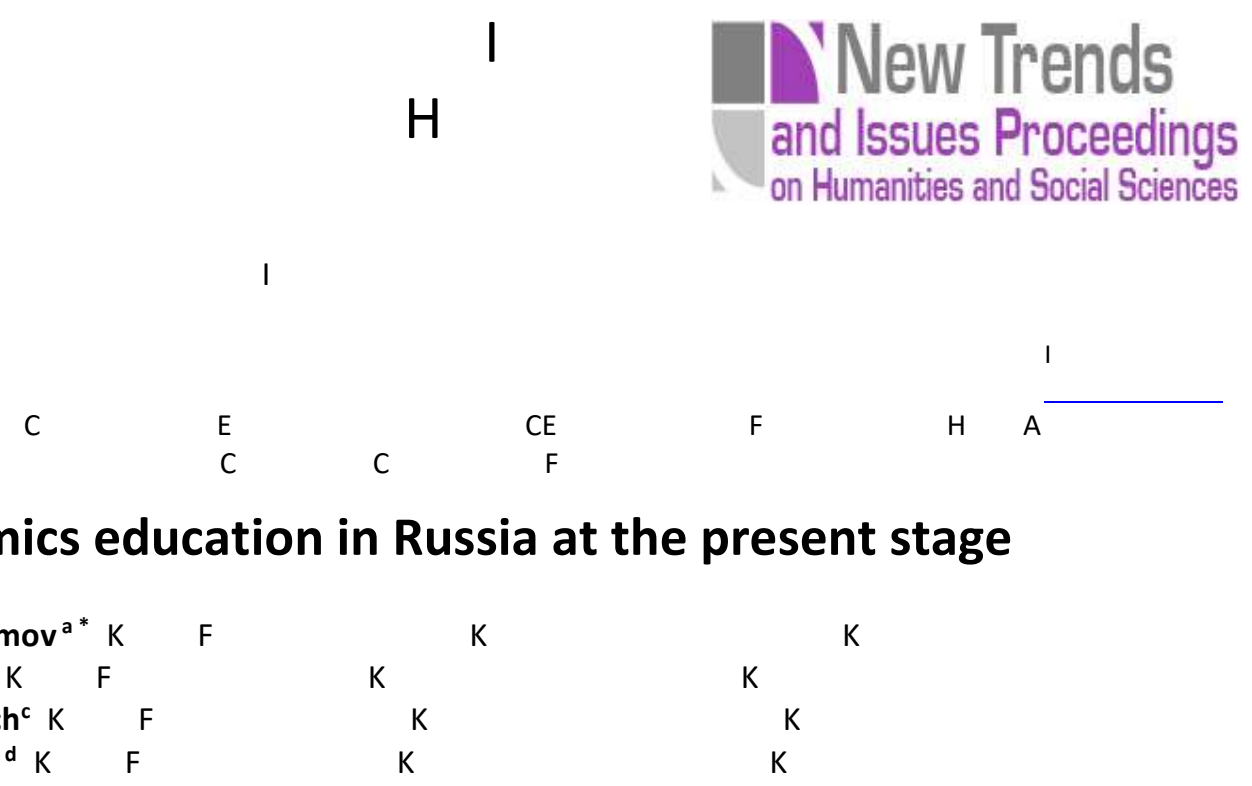

$\begin{array}{rlll}\mathrm{CE} & \mathrm{H} & \mathrm{H} \\ \mathrm{F} & & \mathrm{A}\end{array}$

\title{
Economics education in Russia at the present stage
}

Almaz Rafisovich Gapsalamov ${ }^{\mathrm{a}}{ }^{*} \mathrm{~K} \quad \mathrm{~F}$ Vasilev Vladimir Lvovich $^{\text {b }} \mathrm{K}$ Ilin Aleksandr Gennadevich ${ }^{c} K \quad F$ Bahvalov Sergey Yurevich ${ }^{d} \mathrm{~K} \quad \mathrm{~F}$ Sharipov R. R. K

Suggested Citation: G A G

A
K

K $\mathrm{K}$ $\mathrm{K}$

A $\quad$ KAl $\quad$ K
C
A
A

Abstract

K $\quad E$

*ADD E F C E $\quad$ DE CE Almaz Rafisovich Gapsalamov K F 
1. Introduction

B

A

$\mathrm{F}$

I

A

$\mathrm{F}$

2. Methodological Framework 
G

A

G

I

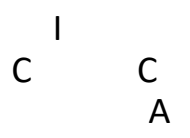

C

A

E
D

D

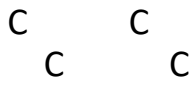

C

A

E

A

C

K

I

G

A

3. Results 
G 
A

A

4. Discussion

D

A

A

A

5. Conclusion

$B^{E}$ C

I

C 
E

\section{References}

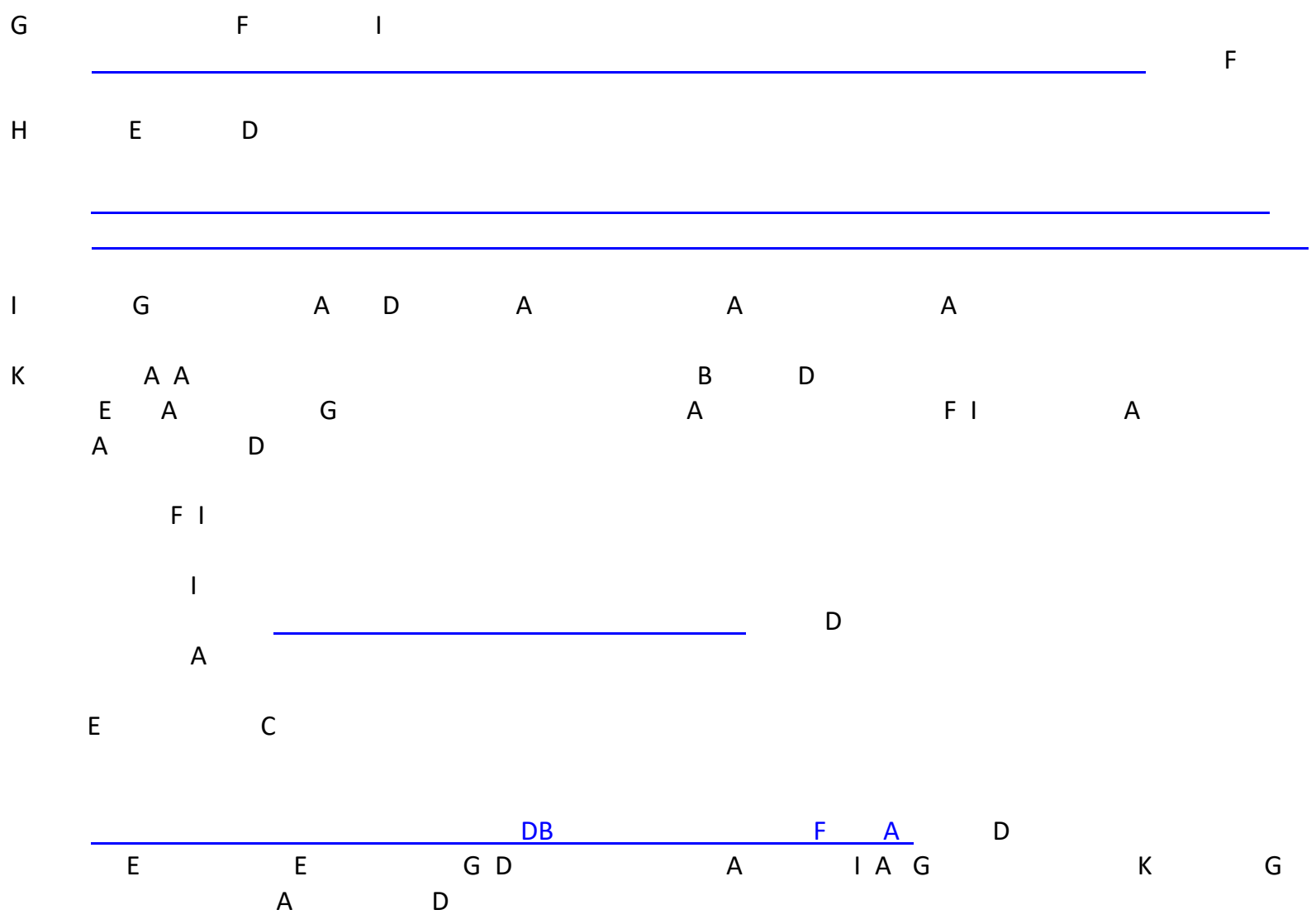

